\title{
School gardening in Bhutan: Evaluating outcomes and impact
}

\author{
Pepijn Schreinemachers ${ }^{1}$ - Bal Bdr Rai ${ }^{2}$ Desang Dorji ${ }^{3}$ Hsiao-pu Chen ${ }^{4}$. \\ Thinley Dukpa ${ }^{2} \cdot$ Namgay Thinley $^{5} \cdot$ Passang Lhamo Sherpa $^{6} \cdot$ Ray-Yu Yang ${ }^{4}$
}

Received: 31 August 2016/Accepted: 16 March 2017 /Published online: 29 April 2017

(C) The Author(s) 2017. This article is an open access publication

\begin{abstract}
School gardening interventions have been touted as an effective approach to improve children's eating habits in developed countries, but there is little evidence for their impact in developing countries. We studied the combined effect of school gardens linked to complementary lessons and promotional activities on the eating behavior and nutritional status of 9- to 15-year-old schoolchildren in Bhutan. We also studied the effect on a range of secondary indicators derived from the impact pathway. We used data from 468 schoolchildren in 9 control and 9 treatment schools following a randomized controlled trial design. We found that the school gardening intervention significantly increased children's awareness about vegetables, their knowledge about sustainable agriculture, and their preferences for healthier foods. We found an 11.7-percentage point increase in the probability that children included vegetables in their meals $(p<0.05)$, but not in the number of different fruits or vegetables consumed. These results support the idea that
\end{abstract}

Pepijn Schreinemachers

pepijn.schreinemachers@worldveg.org

Bal Bdr Rai

raibb@yahoo.com

Desang Dorji

desang@moe.gov.bt

Hsiao-pu Chen

hsiaopu.chen@gmail.com

Thinley Dukpa

dukpel85@gmail.com

Namgay Thinley

nthinley123@gmail.com

Passang Lhamo Sherpa

splham@gmail.com comprehensive school garden interventions, combining gardening with education and promotion, can positively influence food preferences and food behavior in developing countries.

Keywords Education · Food behavior - Vegetables · Malnutrition · Nutrition-sensitive agriculture $\cdot$ Impact evaluation $\cdot$ Randomized controlled trial

\section{Introduction}

Eating habits and food attitudes established early in life tend to persist through to adulthood (Birch 1999; Cooke 2007; Kelder et al. 1994). This understanding has created renewed interest in school-based interventions to influence the dietary choices of young children (e.g. Sharma 2007; Jaime and Lock 2009; Wansink et al. 2012; Olsen et al. 2012).

Ray-Yu Yang

ray-yu.yang@worldveg.org

1

World Vegetable Center, P.O. Box 1010 (Kasetsart), Bangkok 10903, Thailand

2 Council for RNR Research of Bhutan (CoRRB), Ministry of Agriculture \& Forests, Royal Government of Bhutan, School Agriculture Program (SAP), Thimphu, Bhutan

3 Department of School Education, Ministry of Education, School Health \& Nutrition Division (SHND), Thimphu, Bhutan

4 World Vegetable Center, P.O. Box 42, Shanhua Tainan 74199, Taiwan

5 Horticulture Division, Department of Agriculture, Ministry of Agriculture and Forests, P.O. Box 392, Thimphu, Bhutan

6 Faculty of Nursing and Public Health, P.O. Box 298, Thimphu, Bhutan 
School gardening is one such intervention that is supported by a rapidly growing literature.

However, the empirical basis for nutritional impact of school gardening on children remains small. Most previous studies have collected data from one or a handful of schools from which is it difficult to generalize (Langellotto and Gupta 2012). Selection bias might also be a problem as there is a lack of use of experimental methods (Blair 2009). Most importantly, nearly all previous studies were conducted for high income countries, mostly in the United States (e.g. Blair 2009; Skelly and Bradley 2007; Ozer 2007; Ratcliffe et al. 2011; Christian et al. 2014). The results from these studies cannot be generalized to developing countries because the type and extent of malnutrition is very different, as is the socio-economic context in which schools operate.

It is therefore unknown if school gardening interventions are a suitable approach to address malnutrition in lower income countries. The question is important because these countries are strongly affected by child malnutrition as evidenced by high levels of child stunting and wasting. This study used data for Bhutan where child malnutrition is a severe problem; an estimated $35 \%$ of preschool children are affected by stunting (Zangmo et al. 2012) and an estimated 28\% of school-aged children are affected by vitamin A deficiency (Singh and West 2004).

The objective of this study is to test the hypothesis that school gardens linked to complementary lessons and promotional activities about gardening and nutrition have a positive effect on the eating behavior of 9- to 15-year-old schoolchildren in Bhutan. We additionally tested a range of secondary hypotheses, derived from the impact pathway of the intervention, namely that the intervention raises children's awareness about healthier food items, increases their knowledge about sustainable agriculture and food, and strengthens their preferences for eating healthier foods.

\section{Intervention design and impact pathway}

Since 2000, the government of Bhutan has introduced the School Agricultural Program (SAP) in about 300 of its 549 schools, ranging from primary to higher secondary schools across the country (CoRRB 2014). The program, which is jointly implemented by the Ministry of Agriculture \& Forests and the Ministry of Education, tries to supplement the diets of schoolchildren and teaches them agricultural skills as a part of a holistic education that raises awareness about employment opportunities in the agricultural sector. Schools that are part of the program have been able to supply their school feeding program with about $20 \%$ of fresh vegetable needs and $35 \%$ of animal produce needs such as pork and eggs (CoRRB 2014). This is important because the World
Food Program, which currently supplies the school feeding program, will wind down its support by 2018 (CoRRB 2014).

This study evaluates a pilot school garden program developed within the context of the "Vegetables Go to School" project, funded by the Swiss Agency for Development Cooperation (SDC) through the World Vegetable Center. This pilot scheme builds on the experience gained with SAP but implemented a stronger linkage between school gardening and education. Different from SAP, the focus is more on educating students about the importance of vegetable production and consumption for their nutrition and health as well as the importance of good water, sanitation and hygiene (WASH), which were otherwise independent activities in schools. If successful, this model of synergizing school vegetable gardening, WASH and nutrition in schools could be used to improve SAP.

The pilot research project was jointly designed and implemented by the Ministry of Agriculture \& Forests and the Ministry of Education with technical support from the Faculty of Nursing and Public Health in Thimphu and international project partners, including the World Vegetable Center, the Swiss Tropical and Public Health Institute and the University of Freiburg, Germany. Strengthening the collaboration between agriculture, education and nutrition with the aim of improving the nutritional status of schoolchildren was an important aspect of the project.

The main impact pathway assumes that the program raises children's awareness about fruit and vegetables, enhances their knowledge of the importance of fruit and vegetables for their health, promotes their preferences for healthy foods, and stimulates them to eat more of these foods, which in turn will improve their nutritional status (Fig. 1). The intervention had three components that were concurrently implemented in all intervention schools:

The first component was a school garden for the cultivation of nutrient-dense vegetables by the schoolchildren under the guidance of teachers and with the support of parents and the local community. The local project team taught the teachers how to establish and manage the school garden through a training course before the start of the school year. Quality vegetable seed, gardening tools and other equipment as required were supplied. Together with local agriculture extension services the project team monitored the gardens and provided technical assistance as needed.

The second component was comprised of teaching materials for weekly lessons in gardening, nutrition, and water, sanitation and hygiene (WASH). The teaching emphasized learning by doing and was regularly conducted in the school garden. It was introduced as an extracurricular activity of the school agriculture club, which the children could join voluntarily. But the garden was also used as a hands-on teaching tool in science and geography in high schools where agriculture was part of the school curriculum. The lessons were 


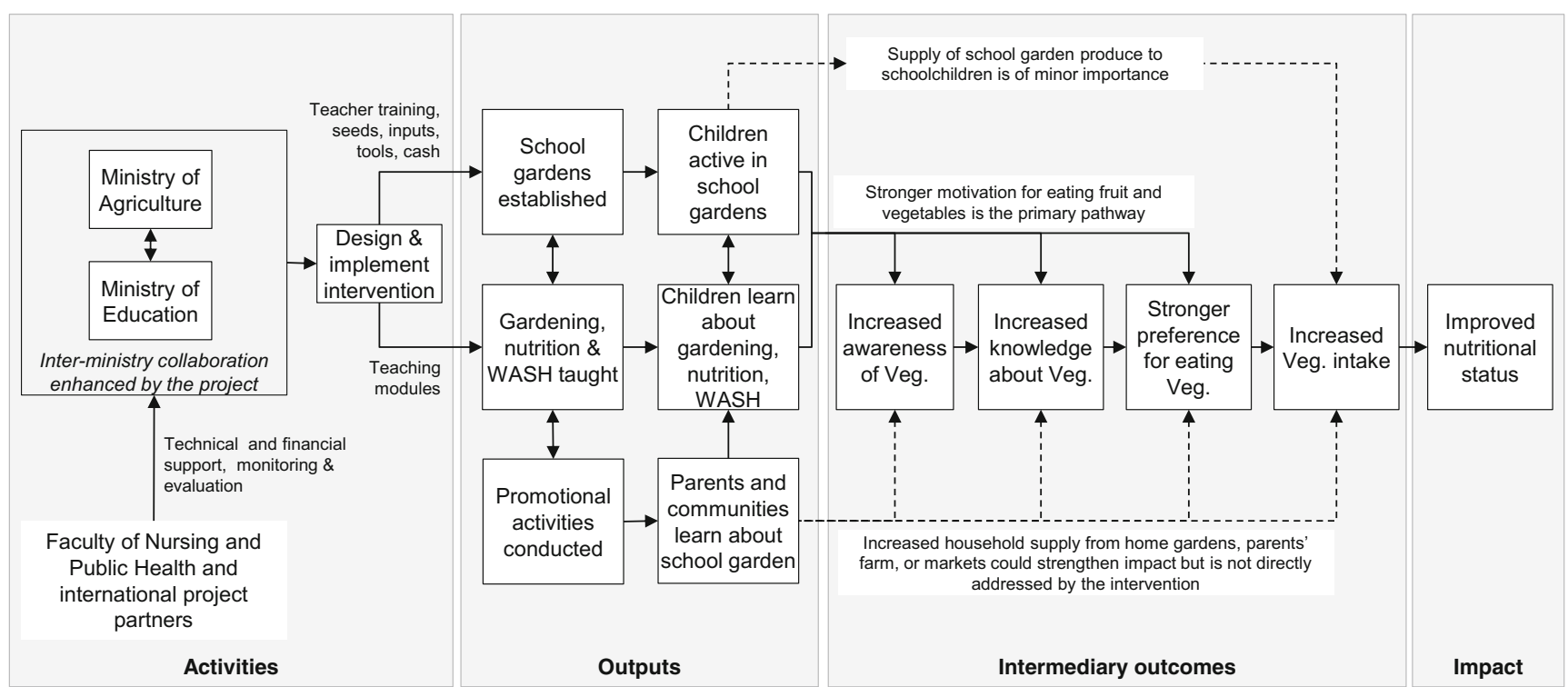

Fig. 1 Impact pathway of the school garden intervention in Bhutan

taught by a trained agriculture teacher for $2 \mathrm{~h}$, mostly on Saturday mornings. WASH activities were accompanied by the installation of basins for hand washing, the availability of soap, and a supply of toothbrushes. This builds on the understanding that the relationship between vegetable intake and improved nutritional status is mediated by factors such as the prevalence of diseases and parasitic infections that impede the body's uptake and absorption of nutrients. Through practical demonstrations, children learned about the importance of tooth brushing and hand washing as well as washing feet, legs and hands after gardening work and the importance of washing vegetables well before consumption.

The third component consisted of promotion activities to reinforce the lessons learned and to strengthen impact. The activities included poster displays, poem displays on school boards, songs, nutrition charts, vegetable charts, pledges (e.g. "I promise to eat more vegetables and wash my hands before I eat!"), and essays written by students. The purpose was to promote the project concept to the schoolchildren and their parents. There was also a competition between the intervention schools to make the best school garden with a trophy given to the winning school. Parents were much involved with the school gardens, helping with land preparation and crop care and receiving mini seed packets as a token of appreciation. Some parents provided advice, gardening tools and other materials and advised school teachers on crops and varieties to grow. Teachers also visited the parents at home and encouraged them to grow and serve more leafy vegetables.

The availability of an increased vegetable supply from the school garden could potentially make a direct contribution to increased vegetable consumption among schoolchildren, but this was not the main strategy of the project. School gardens were relatively small, ranging from 1000 to $4000 \mathrm{~m}^{2}$, and the harvest would not be enough to feed hundreds of schoolchildren. The produce from the garden was sold at a low price to the school feeding program to supplement meals served in the school canteen, or, if there was no canteen, distributed to the children and teachers for home consumption. Produce occasionally was sold to the community to generate funds for sustaining the garden program in schools.

Teachers and children were generally enthusiastic about the school garden project, but there were also challenges. Freeroaming animals such as monkeys, porcupines, rabbits, deer and wild pigs destroyed the vegetables in some school gardens; steel posts with barbed iron wire fences were therefore installed to protect the gardens. It was sometimes difficult to find enough flat land as the terrain in some locations was very steep. Low soil fertility also was a problem, so composting to improve soil fertility was introduced. Some teachers felt burdened by the extra workload and there was a problem of teachers changing schools. As an incentive, successful teachers were rewarded with a study visit within the region. Another problem was that vegetables could be produced for only 5-6 months a year because of the cold climate, particularly at high altitudes. Finally, the schools were located at great distances, which made it difficult for the project staff to visit them regularly and provide technical support.

\section{Methods}

\section{Experimental design}

The study was included in the Registry for International Development Impact Evaluations (http://ridie.3ieimpact.org/) as Study ID 55d344c556559. A randomized controlled trial 
design was used to assess the combined impact of the three intervention components. The main advantage of randomization is that it reduces the potential of selection bias. If schools were purposively selected by the project implementers, then schools with favorable conditions for a school garden - for example, an enthusiastic and innovative principal or a schoolyard with good planting conditions - would be more likely to receive the project intervention and also more likely to show a positive impact than the average school, which would give an upward bias to the estimated impact.

Schools for the study were selected from 11 of Bhutan's 20 districts (dzongkhags) in the western and central parts of the country to facilitate access by the project team during the pilot phase. A list of 80 schools was created that met the following criteria: (a) reachable within two days travel from the capital Thimphu; (b) interest and commitment of the school principal and the availability of a teacher to teach gardening; (c) availability of at least $1214 \mathrm{~m}^{2}(0.30$ acres $)$ of land suitable for gardening and a feasible source of water; (d) acceptance of the project by the parents in the community. These criteria helped to create a more meaningful comparison between control and treatment schools, thereby improving the study's internal validity. The obvious drawback is that the results cannot be generalized to all schools in the country, and the external validity is hence compromised.

Thirty-five schools were randomly selected from this list and randomly assigned to one of three categories: 15 schools to receive the treatment in $2014 ; 10$ schools to receive the treatment in 2015; and 10 schools as a control (Fig. 2). Schools in the treatment groups received all three intervention components described above. Data for this study were collected from the 2015 treatment group and the control group. The original plan was to collect data for the 2014 treatment group as well, but the questionnaires were developed late and the opportunity was missed. One control school and one treatment school did not complete baseline data collection before the start of the intervention, which reduced the sample to 18 schools: 9 intervention and 9 control schools. Data were collected at the start and at the end of the school year from a random sample of schoolchildren from grades 3-6. Informed consent was obtained from the parents of the participating children. The Ministry of Agriculture \& Forests and the Ministry of Education both approved the study.

\section{Data}

Outcome indicators were taken from the project's impact pathway (Fig. 1), which assumes stepwise changes in the children's food awareness, knowledge, and preferences (intermediary outcomes) eventually leading to improvements in eating behavior and nutritional status (primary outcomes). Improvements in nutritional status are unlikely to be achieved within 8 months and it is therefore important to quantify intermediate outcomes that may show progress toward impact. Measurement methods were identified from a review of previous evaluations of school-based interventions. Each indicator is introduced in the following list:

1. Awareness of fruit and vegetables was measured by children's ability to correctly identify the names of 20 common fruit and vegetables from color photos.

2. Knowledge about food and nutrition was measured in three ways: (a) schoolchildren were shown photos of 15 food items and had to tick which of these were rich in vitamins. This test was adjusted from Parmer et al. (2009); (b) Schoolchildren were given 10 statements about the association between food and nutrients on the one hand and health and body functions on the other hand (e.g. "Vegetables help to protect against infections") and had to indicate whether they agreed or disagreed. This broadly followed the method described in Oldewage-Theron and Egal (2010); (c) Schoolchildren were given 10 statements and asked to indicate whether they agreed or disagreed with each one (e.g. "Dirty hands can make me sick").

3. Knowledge about sustainable agriculture was measured in two ways: (a) schoolchildren were shown 12 photos of common garden insects (e.g. caterpillars, earthworms, spiders, bees) and asked to tick those that they thought damage crops. (b) Schoolchildren were shown 10 photos each showing a sequence of three vegetable plantings (e.g. tomato, followed by eggplant, and again followed by tomato) and had to indicate whether growing these crops one after another was good, not good, or don't know. For each knowledge test we calculated the percentage of correct answers and then calculated the overall average. About half of the choices were factually correct for all methods.

4. Increased awareness and knowledge about food gained through hands-on practice with the school garden is expected to stimulate the desire of schoolchildren to eat more fruit and vegetables. Progress towards this end was measured in two ways: (a) schoolchildren were shown 12 photos of different vegetables and asked to rate their liking for them. This test was adapted from Lineberger and Zajicek (2009), Parmer et al. (2009) and Heim et al. (2009) who did similar tests to evaluate children's liking for vegetables in the United States; (b) Schoolchildren were presented with photos of 10 snack choices, each choice including one healthy (unprocessed) and one less healthy (processed) food choice and had to select the one they preferred as a snack. This was adapted from Lineberger and Zajicek (2009) and Morris and Zidenberg-Cherr (2002).

5. Improvements in the above indicators were expected to translate into greater fruit and vegetable consumption. This was measured using a 24-h recall method in which 
Fig. 2 Flow diagram showing progress through the randomized controlled trial

\section{Allocation: \\ Baseline data collection: \\ Endline data collection:}

Analysis: the children had to record all food items (including meals, snacks and drinks) that they ate or drank the previous day, during the day and night, whether at home or outside the home. From this we quantified two binary indicators for whether the child had consumed any vegetables or fruit in the previous $24 \mathrm{~h}$ and two integer variables counting the number of different vegetables or fruits consumed.

6. Long-term improvements in dietary behavior should lead to improved nutritional status, in the absence of disease and parasitic infection. Body height and weight were measured for each child and together with data on age and sex converted into z-scores following Vidmar et al. (2013) and using WHO Child Growth Standards (World Health Organization 2007). Teachers were trained in collecting these data following WHO guidelines. We only used the height-for-age z-score.

The data were recorded using a structured questionnaire. Most survey questions were illustrated with color photos and had multiple choice answers to aid the children's comprehension. All text was brief and the phrasings were simple. The questionnaire was designed in English and pre-tested in an out-of-sample school. Pre-intervention data were collected at the start of the school year in March-April 2015 and postintervention data were collected at the end of the school year

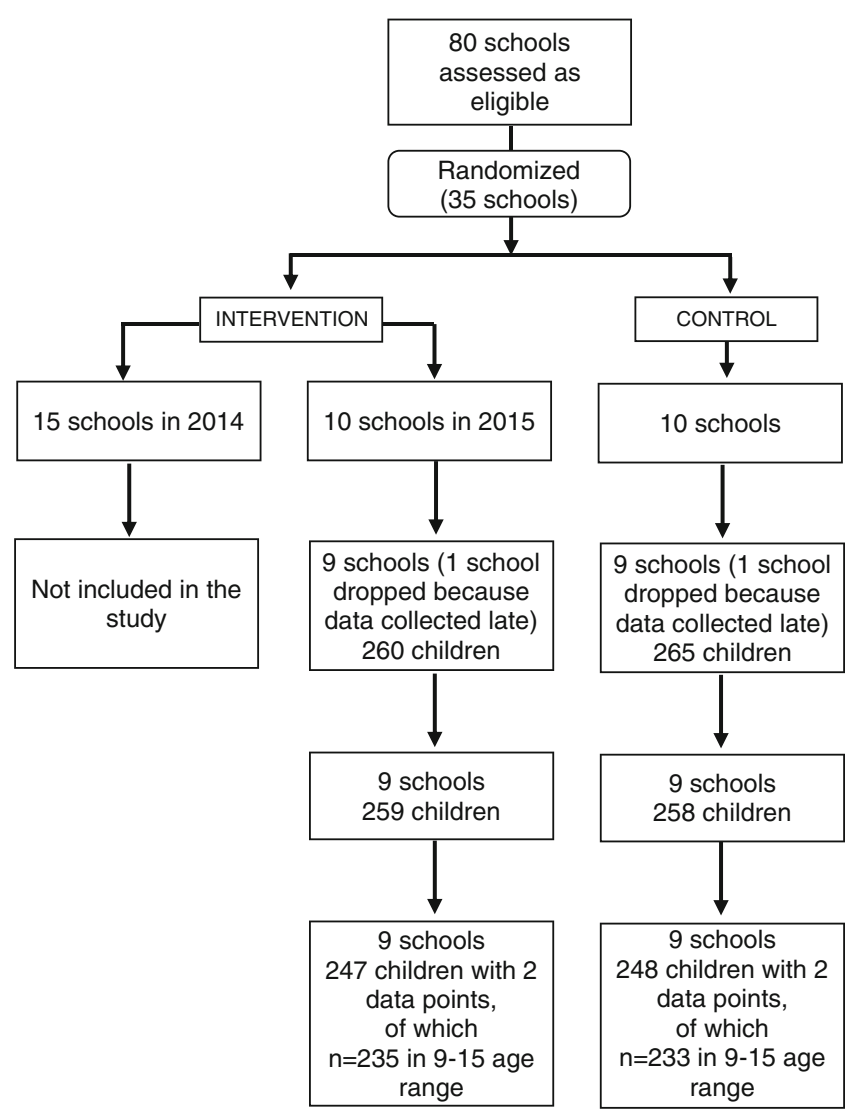

in October-November 2015. There was a 5.5\% sample attrition between baseline and endline (see also Fig. 2). Children's age at baseline ranged from 6 to 18 years, but there were only 17 observations for children younger than 9 and only $10 \mathrm{ob}-$ servations for children older than 15 . We therefore excluded schoolchildren outside the 9-15 years age range from the analysis, which reduced the sample by another $5.5 \%$. The final sample included 468 schoolchildren. The questionnaires and anonymized data are available from the authors upon request.

\section{Analysis}

We used a linear regression model to estimate the impact of the intervention:

$\mathrm{Y}_{\mathrm{it}}=\alpha+\beta_{1}\left(\mathrm{~T}_{\mathrm{i}} \times \mathrm{v}_{\mathrm{t}}\right)+\beta_{2}\left(\mathrm{~T}_{\mathrm{i}}\right)+\beta_{3}\left(\mathrm{v}_{\mathrm{t}}\right)+\beta_{4} \mathrm{Z}_{\mathrm{it}}+\varepsilon_{\mathrm{it}}$

where $Y_{\text {it }}$ are the outcome indicators defined above for child $i$ at time $t . \mathrm{T}_{\mathrm{i}}$ is the variable that indicates whether a child is in a treatment or control school and $\mathrm{v}_{\mathrm{t}}$ indicates the survey round (baseline or endline). The parameter of interest is $\beta_{1}$, which is the average treatment effect. It is defined as the difference in mean outcomes between schoolchildren in schools assigned to the treatment and schoolchildren in schools assigned to the control. 
The estimation controls for $Z_{i t}$, which is a set of time invariant child and household characteristics, including the child's age at the baseline (in years), sex ( $1=$ female), and other binary variables that capture whether the parents have their own farm, whether the household has their own vegetable garden, and whether the child has to walk to school for more than $30 \mathrm{~min}$ per day. The parameter $\alpha$ is a constant, representing the average level of an outcome variable at the baseline for the control group. $\varepsilon_{i t}$ is a mean-zero error term.

The analysis was done using STATA. For outcome variables expressed as percentages (awareness, knowledge and preferences), we used a generalized linear model (GLM) with a binomial family for the error distribution and a logit link for the dependent variable as recommended by Papke and Wooldridge (1996). For binary outcome variables (whether the child had consumed vegetables or fruits the previous day) we used a probit regression. A poisson regression was used to parameterize the model for the number of different vegetables and fruits consumed the previous day. Finally, we employed ordinary least squares (OLS) to parameterize the model for the height-for-age z-scores. A cluster effect was added to all regression models because schools are the unit of intervention but schoolchildren are the unit of observation. Means, standard deviations and t-values were also clusteradjusted.

We further analyzed heterogeneous effects by introducing interaction terms to the model (following the example of Jones and de Brauw 2015):

$\mathrm{Y}_{\text {it }}=\alpha+\beta_{1}\left(\mathrm{~T}_{\mathrm{i}} \times \mathrm{v}_{\mathrm{t}}\right)+\beta_{2}\left(\mathrm{~T}_{\mathrm{i}}\right)+\beta_{3}\left(\mathrm{v}_{\mathrm{t}}\right)+\beta_{4} \mathrm{X}_{\mathrm{it}}+$

$\mathrm{B}_{5}\left(\mathrm{X}_{\mathrm{it}} \times \mathrm{T}_{\mathrm{i}}\right)+\beta_{6}\left(\mathrm{X}_{\mathrm{it}} \times \mathrm{v}_{\mathrm{t}}\right)+\beta_{7}\left(\mathrm{X}_{\mathrm{it}} \times \mathrm{T}_{\mathrm{i}} \times \mathrm{v}_{\mathrm{t}}\right)+\beta_{8} \mathrm{Z}_{\mathrm{it}}+\varepsilon_{\mathrm{it}}$

where $\beta_{7}$ is the parameter of interest that shows the interaction between average treatment effect and the variable that identifies subpopulations in the sample $\left(\mathrm{X}_{\mathrm{it}}\right)$. We studied whether the effect of the school garden intervention on the number of different vegetables consumed was significantly different from schools with or without a school feeding program. We also analyzed the heterogeneous effects for schoolboys vs. schoolgirls, for children whose parents were engaged in agriculture, for those who have a vegetable garden at home, and for schools in rural vs. urban areas. Each of these effects was studied in a separate regression model.

\section{Results}

The average age of the schoolchildren in the sample was 11.8 years (Table 1). Girls made up $57 \%$ of the treatment group and $46 \%$ of the control group with the difference being significant $(p<0.05)$. None of the other variables listed in the table were significantly different between treatment and control. Schoolchildren often had to walk to school over long distances. Parents were typically involved in agriculture and more than $90 \%$ had a vegetable garden at home. Only a minority of the schoolchildren ate most meals together with their parents, while only $60 \%$ ate dinner together. Most schools ( $81 \%$ in the control and $65 \%$ in the intervention group) provided lunch to the schoolchildren, some of which were boarding schools that provided all meals.

Table 2 shows the means for the outcome variables at baseline and endline. Two outcome indicators (awareness and preferences) were significantly different $(p<0.05)$ between the control and intervention groups at the baseline, despite the random allocation (Table 3). This might be a due to the small sample of schools and we will return to this in the discussion. Differences between control and treatment at the endline were mostly insignificant with the exception of knowledge about sustainable agriculture $(p<0.01)$.
Table 1 Average characteristics of the sample of schoolchildren in Bhutan at baseline, 2015

\begin{tabular}{llll}
\hline Characteristic & $\begin{array}{l}\text { Control } \\
(n=233)\end{array}$ & $\begin{array}{l}\text { Treatment } \\
(n=235)\end{array}$ & $p$-value \\
\hline Age (years) & 11.9 & 11.6 & 0.37 \\
Female (\%) & 57.1 & 45.5 & 0.04 \\
Walk to school for more than 30 min/day (\%) & 39.5 & 34.0 & 0.64 \\
Household size (persons) & 5.2 & 5.5 & 0.69 \\
Vegetable garden at home? (\%) & 91.0 & 86.8 & 0.41 \\
Eat all meals together with parents (\%) & 23.6 & 34.0 & 0.47 \\
Only eat dinner together with parents (\%) & 60.9 & 58.3 & 0.87 \\
Parents are farmers (\%) & 73.0 & 78.7 & 0.56 \\
Boarding school (\%) & 36.9 & 12.8 & 0.30 \\
School with feeding program (\%) & 80.7 & 65.1 & 0.31 \\
School in rural area (\%) & 88.4 & 65.1 & 0.30 \\
\hline
\end{tabular}


Table 3 shows the regression results. Controlling for all other variables included in the regression, the school garden intervention increased children's awareness of fruit and vegetables by 18.0 percentage points $(p<0.01)$, their knowledge of sustainable agriculture by 15.2 percentage points $(p<0.05)$, and their preferences for consuming fruit and vegetables by 9.5 percentage points $(p<0.05)$. There was a significant 13.9 percentage point increase in food and nutrition knowledge between baseline and endline, but this increase was not statistically different between control and treatment.

The intervention had a significant $(p<0.05)$ effect on children's probability of consuming vegetables the previous day, which increased by 11.7 percentage points (Table 3). There was no significant effect on children's probability of fruit consumption and neither was there a significant effect on the number of different fruits or the number of different vegetables consumed. However, children whose families had a vegetable garden at home consumed a significantly greater number of different fruits and vegetables. The age of the child also had a positive effect on the number of vegetables consumed. Finally, the study did not find a significant effect of the intervention on children's height-for-age z-scores within the first 6-8 months of the project. We will return to this in the discussion.

Table 4 shows the results of introducing interaction terms between the average treatment effect and exogenous variables following Eq. 2. The outcome variable was the number of different vegetables the children had consumed in the previous day. It shows that there were no significant synergies between the school gardens on the one hand and the school feeding program, parents working in agriculture, sex of the child, rural areas, and having a home vegetable garden on the other hand. The results do confirm that children whose families had a vegetable garden at home were more likely to eat a greater number of different vegetables, but there was no synergy between school gardens and home gardens. It must, however, be kept in mind that the variation in such schoollevel variables was small as there were only 18 schools in the sample.

Table 2 Pre-and post-intervention levels of outcome indicators used to measure the impact of the school garden intervention on 9-15 year old schoolchildren in Bhutan, 2015, standard deviations in parentheses

\begin{tabular}{|c|c|c|c|c|c|c|c|c|}
\hline \multirow[t]{2}{*}{ Outcome indicators } & \multicolumn{4}{|c|}{ Baseline data } & \multicolumn{4}{|c|}{ Endline data } \\
\hline & $\mathrm{C}$ & $\mathrm{T}$ & $\mathrm{T}-\mathrm{C}$ & Sign. & $\mathrm{C}$ & $\mathrm{T}$ & $\mathrm{T}-\mathrm{C}$ & Sign. \\
\hline \multicolumn{9}{|l|}{ Awareness } \\
\hline$-\%$ of fruit and vegetables correctly named & $\begin{array}{l}46.5 \\
(20.6)\end{array}$ & $\begin{array}{l}28.1 \\
(19.3)\end{array}$ & -18.4 & $\begin{array}{l}<0.01 \\
* * *\end{array}$ & $\begin{array}{l}74.5 \\
(19.5)\end{array}$ & $\begin{array}{l}75.9 \\
(19.0)\end{array}$ & 1.4 & 0.81 \\
\hline \multicolumn{9}{|l|}{ Knowledge } \\
\hline$-\%$ of correct answers on sustainable agriculture & $\begin{array}{l}55.5 \\
(14.1)\end{array}$ & $\begin{array}{l}50.9 \\
(14.8)\end{array}$ & -4.6 & 0.26 & $\begin{array}{l}56.8 \\
(12.1)\end{array}$ & $\begin{array}{l}67.3 \\
(16.7)\end{array}$ & 10.5 & $\begin{array}{l}0.06 \\
*\end{array}$ \\
\hline$-\%$ of correct answers on food, nutrition \& WASH & $\begin{array}{l}61.8 \\
(14.5)\end{array}$ & $\begin{array}{l}69.3 \\
(11.6)\end{array}$ & 7.5 & 0.16 & $\begin{array}{l}76.4 \\
(11.3)\end{array}$ & $\begin{array}{l}77.8 \\
(10.9)\end{array}$ & 1.4 & 0.67 \\
\hline \multicolumn{9}{|l|}{ Preferences } \\
\hline$-\%$ of fruit and vegetables liked & $\begin{array}{l}68.2 \\
(16.1)\end{array}$ & $\begin{array}{l}61.8 \\
(16.8)\end{array}$ & -6.4 & $\begin{array}{l}0.03 \\
* *\end{array}$ & $\begin{array}{l}69.5 \\
(16.5)\end{array}$ & $\begin{array}{l}72.7 \\
(16.6)\end{array}$ & 3.2 & 0.44 \\
\hline \multicolumn{9}{|l|}{ Eating Behavior (24 h) } \\
\hline$-\%$ of children that ate vegetables & 90.1 & 80.0 & -10.1 & 0.28 & 92.7 & 95.3 & 2.6 & 0.61 \\
\hline$-\%$ of children that ate fruits & 5.2 & 8.1 & 2.9 & 0.50 & 23.6 & 26.0 & 2.4 & 0.85 \\
\hline -Number of different vegetables eaten & $\begin{array}{l}2.0 \\
(1.6)\end{array}$ & $\begin{array}{l}1.7 \\
(1.6)\end{array}$ & 0.3 & 0.99 & $\begin{array}{l}2.5 \\
(1.5)\end{array}$ & $\begin{array}{l}2.4 \\
(1.5)\end{array}$ & -0.1 & 1.00 \\
\hline -Number of different fruits eaten & $\begin{array}{l}0.1 \\
(0.2)\end{array}$ & $\begin{array}{l}0.1 \\
(0.3)\end{array}$ & 0.0 & 0.77 & $\begin{array}{l}0.3 \\
(0.7)\end{array}$ & $\begin{array}{l}0.4 \\
(0.7)\end{array}$ & 0.1 & 1.00 \\
\hline \multicolumn{9}{|l|}{ Nutritional status } \\
\hline -Height-for-age z-score & $\begin{array}{l}-1.4 \\
(1.3)\end{array}$ & $\begin{array}{l}-1.1 \\
(1.5)\end{array}$ & 0.3 & 0.39 & $\begin{array}{l}-1.0 \\
(1.4)\end{array}$ & $\begin{array}{l}-0.8 \\
(1.5)\end{array}$ & 0.2 & 0.58 \\
\hline Observations (n) & 233 & 235 & & & 233 & 235 & & \\
\hline
\end{tabular}

$C$ Control, $T$ Treatment, Diff Difference, Sign. Significance level, estimated using a chi-squared test for binary variables and a two sample t-test for all other variables. $* * * p<0.01, * * p<0.05, * p<0.10$ 

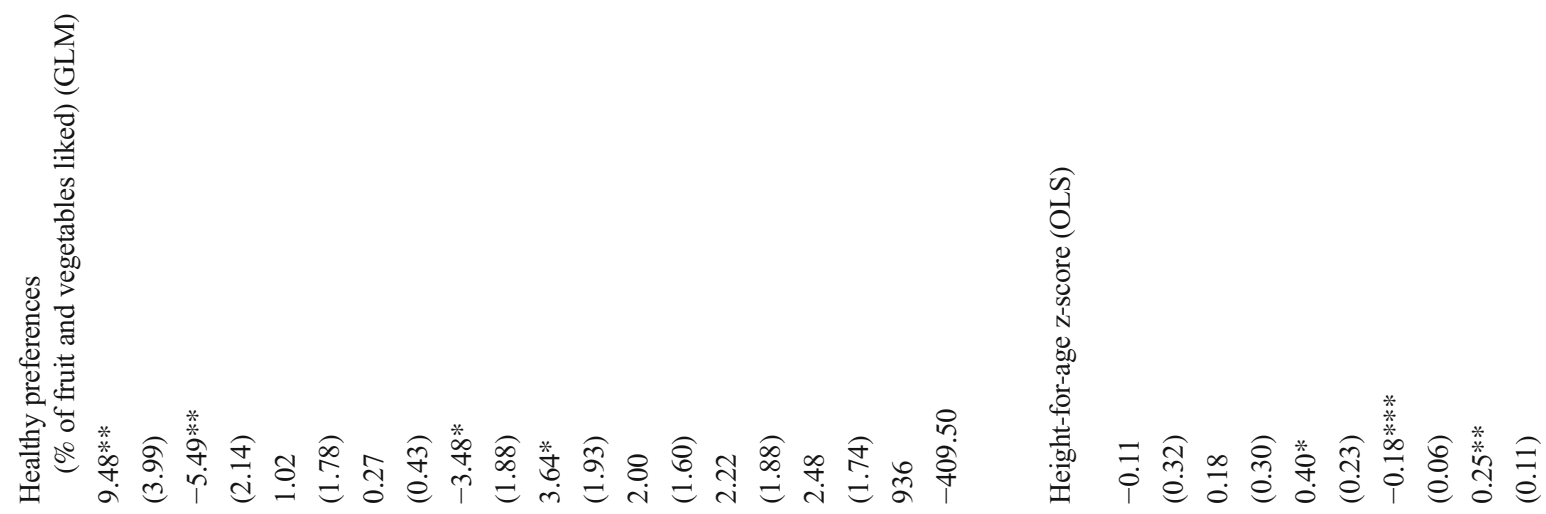

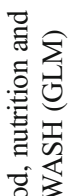

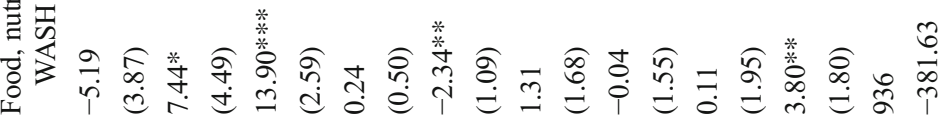

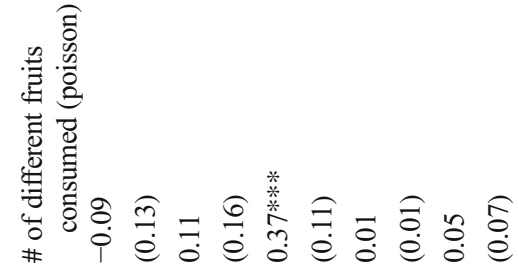

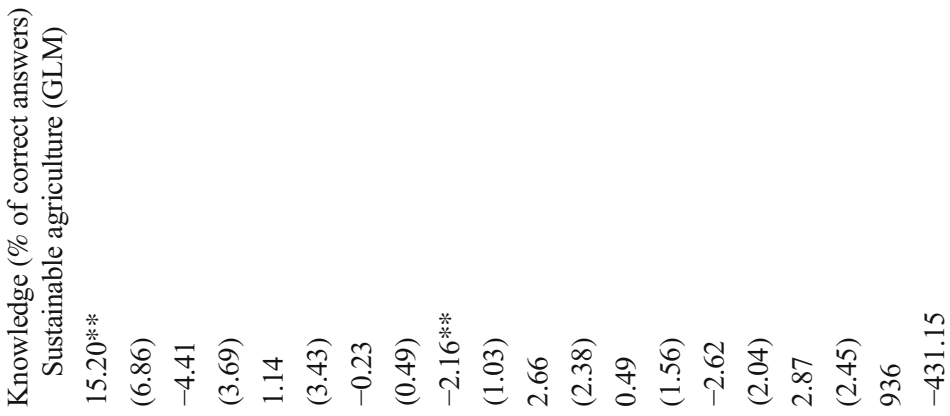

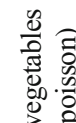

离

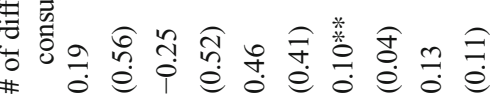

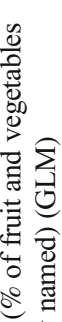

总

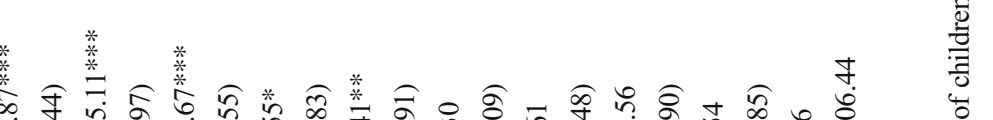

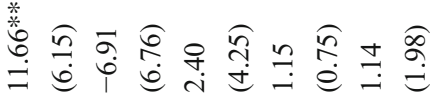

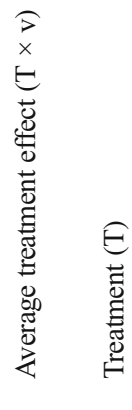

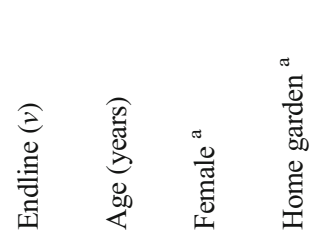

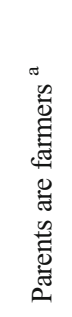

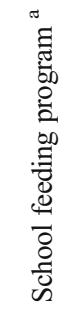

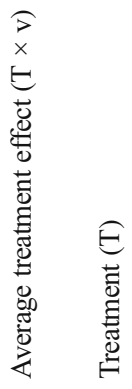

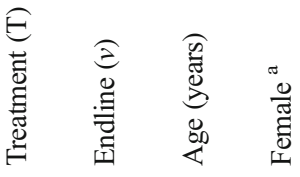




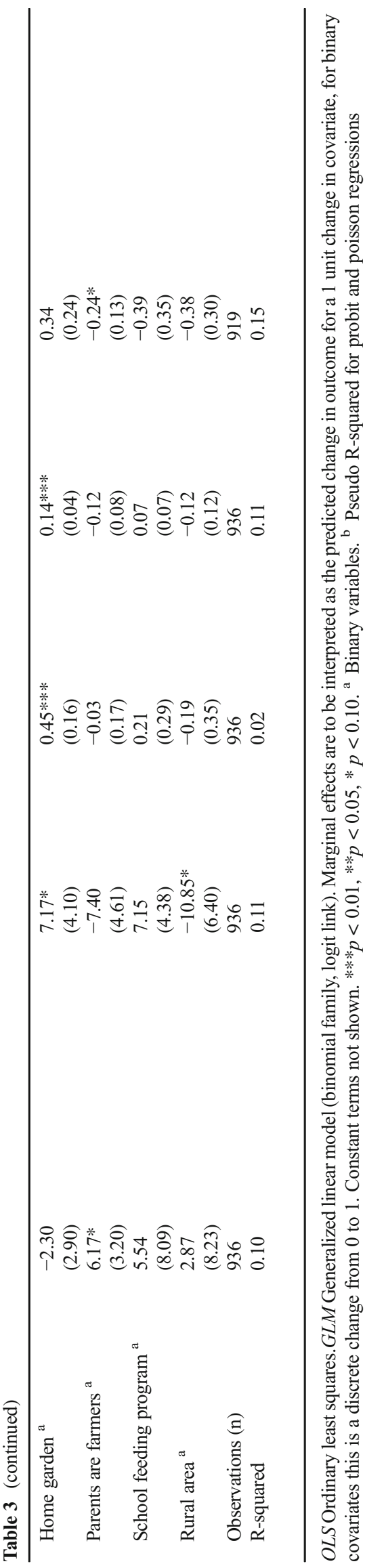

\section{Discussion}

The results of our study support the idea that a comprehensive school garden intervention, combining gardening with education and promotion, has the potential to influence dietary preferences and behavior in lower income countries. We found a significant and positive effect on the likelihood of vegetable consumption, but no significant increase in the number of different vegetables consumed.

The results of our study confirm those of previously published studies in showing that school garden-based nutrition education tends to improve children's awareness, knowledge, and preferences but not always increases vegetable intake levels. For instance, Lineberger and Zajicek (2009) for a study in the United States and Morgan et al. (2010) for a study in Australia found significant improvements in children's preferences for vegetables, but no significant increase in vegetable consumption. Others studies did find significant improvements in children's vegetable consumption (McAleese and Rankin 2007; Parmer et al. 2009; Wang et al. 2010). However, for a study in the United Kingdom, Christian et al. (2014) found no evidence that the average school garden program improved children's knowledge, attitudes, or fruit and vegetable intake.

The findings of the study, and those of the abovementioned previous studies, therefore show that increasing children's vegetable consumption through school gardenbased interventions is a challenging task. We do believe that the combination of gardening and education was an essential aspect of the intervention design. Several other studies have also empirically proved that this combination is more effective than either component alone (e.g. Morgan et al. 2010; Parmer et al. 2009; McAleese and Rankin 2007).

However, for a low income country such as Bhutan, additional aspects need consideration that may not be equally relevant to high income countries. First, parents' awareness and knowledge of nutrition is likely to be low and given their influence on children's eating behavior, it may be important to increase their nutritional knowledge simultaneously with that of their children. Although our intervention involved parents, it did not specifically aim to do this. Furthermore, the effect of our intervention on nutritional knowledge was insignificant (only the effect on agricultural knowledge was significant) and this component therefore needs to be revisited to see if it can be improved. The fact that the likelihood of vegetable consumption increased despite the lack of improvement in nutrition knowledge suggests that increased awareness may also directly influence preferences and behavior.

Second, the supply of vegetables in Bhutan is highly seasonal. For instance, the strong increase in fruit consumption between baseline and endline for both control and treatment is largely due to seasonality. If vegetables are not available in 
Table 4 Heterogeneity in the effect of the school garden intervention on the number of different vegetables consumed among 9-15 year old schoolchildren in Bhutan, 2015, marginal effects at means, standard errors in parentheses

\begin{tabular}{|c|c|c|c|c|c|}
\hline & \multicolumn{5}{|c|}{ Testing for heterogeneity by: } \\
\hline & $\begin{array}{l}\text { School } \\
\text { feeding }\end{array}$ & $\begin{array}{l}\text { Parents are } \\
\text { farmers }\end{array}$ & $\begin{array}{l}\text { Female } \\
\text { children }\end{array}$ & $\begin{array}{l}\text { Home } \\
\text { gardens }\end{array}$ & $\begin{array}{l}\text { Schools in } \\
\text { rural areas }\end{array}$ \\
\hline \multirow[t]{2}{*}{ Average treatment effect $(\mathrm{T} \times \mathrm{v})$} & 0.02 & -0.22 & 0.12 & 0.10 & -0.78 \\
\hline & $(0.94)$ & $(0.91)$ & $(0.62)$ & $(0.69)$ & $(0.61)$ \\
\hline \multirow[t]{2}{*}{ Treatment $(\mathrm{T})$} & 0.92 & 0.06 & -0.06 & -0.28 & $1.80 * * *$ \\
\hline & $(0.83)$ & $(0.66)$ & $(0.56)$ & $(0.49)$ & $(0.42)$ \\
\hline \multirow[t]{2}{*}{ Endline (v) } & 0.28 & $0.71 *$ & 0.46 & 0.42 & $1.33 * * *$ \\
\hline & $(0.77)$ & $(0.43)$ & $(0.40)$ & $(0.45)$ & $(0.09)$ \\
\hline \multirow[t]{2}{*}{ Age (years) } & $0.10 * *$ & $0.10 * *$ & $0.09 * *$ & $0.10 * *$ & 0.10 \\
\hline & $(0.04)$ & $(0.04)$ & $(0.04)$ & $(0.04)$ & $(0.04)^{* *}$ \\
\hline \multirow[t]{2}{*}{ School feeding program ${ }^{a}$} & 0.95 & 0.21 & 0.22 & 0.22 & 0.04 \\
\hline & $(0.78)$ & $(0.29)$ & $(0.29)$ & $(0.29)$ & $(0.28)$ \\
\hline \multirow[t]{2}{*}{ Parents are farmers ${ }^{a}$} & -0.11 & 0.19 & -0.03 & -0.03 & -0.14 \\
\hline & $(0.15)$ & $(0.24)$ & $(0.17)$ & $(0.17)$ & $(0.15)$ \\
\hline \multirow[t]{2}{*}{ Female $^{a}$} & 0.14 & 0.13 & 0.27 & 0.13 & 0.09 \\
\hline & $(0.11)$ & $(0.11)$ & $(0.20)$ & $(0.11)$ & $(0.11)$ \\
\hline \multirow[t]{2}{*}{ Home garden ${ }^{\text {a }}$} & $0.35^{* *}$ & $0.46^{* * *}$ & $0.46^{* * *}$ & 0.40 & $0.38 * *$ \\
\hline & $(0.15)$ & $(0.16)$ & $(0.16)$ & $(0.40)$ & $(0.16)$ \\
\hline \multirow[t]{2}{*}{ Rural area ${ }^{a}$} & -0.27 & -0.18 & -0.20 & -0.19 & $1.57 * * *$ \\
\hline & $(0.30)$ & $(0.35)$ & $(0.35)$ & $(0.35)$ & $(0.37)$ \\
\hline \multirow[t]{2}{*}{ ATE $\times$ School feeding program } & 0.38 & & & & \\
\hline & $(1.14)$ & & & & \\
\hline \multirow[t]{2}{*}{ ATE $\times$ Parents are farmers } & & 0.53 & & & \\
\hline & & $(0.76)$ & & & \\
\hline \multirow[t]{2}{*}{ ATE $\times$ Female } & & & 0.16 & & \\
\hline & & & $(0.49)$ & & \\
\hline \multirow[t]{2}{*}{ ATE $\times$ Home garden } & & & & 0.10 & \\
\hline & & & & $(0.68)$ & \\
\hline \multirow[t]{2}{*}{ ATE $\times$ Rural area } & & & & & 1.10 \\
\hline & & & & & $(0.90)$ \\
\hline Observations (n) & 936 & 936 & 936 & 936 & 936 \\
\hline Pseudo R-squared & 0.03 & 0.02 & 0.02 & 0.02 & 0.03 \\
\hline
\end{tabular}

Estimated using poisson regression. Models also included interaction terms between covariate and Treatment $(\mathrm{T})$ and between covariate and Endline (v), but these were omitted from the table. Marginal effects are to be interpreted as the predicted change in the number of vegetables consumed for a 1 unit change in covariate, for binary covariates this is a discrete change from 0 to 1 . $*^{* *} p<0.01$, **p $p<0.05, * p<0.10{ }^{\text {a }}$ Binary variables schools or in children's homes then children are unable to practice what they have learned. Vegetable availability may therefore need to be addressed in parallel to raising children's vegetable demand and this would need to be addressed at the household and at the community level. The regression results showed that children with a vegetable garden at home consumed a greater number of different vegetables and fruits (Table 3), but there was no significant synergy between home gardens and school gardens (Table 4). The project gave parents who helped with the school garden small packets of vegetable seeds and project team members visited parents at home to encourage vegetable production and consumption, but greater effort may be needed. If this were done within a school garden project then this would substantially increase costs and decrease its scaling potential. Collaboration with agricultural extension agencies is therefore important. This points to the need for coordination among nutrition, health and agricultural interventions, which was one of the main tenets of the project.

Third, schools in low income countries are much more resource-constrained than schools in high income countries with teachers having to teach more children with fewer classroom materials at their disposal. If teachers are already challenged to do their basic job, then it may be hard for them to take on additional responsibilities, which may reduce the 
effectiveness of the intervention. This needs careful deliberation before introducing the intervention to more schools.

Another aspect in which this study is different from those in higher income countries is that most schoolchildren in our study came from households already involved in agriculture. Whereas outdoor playing and the experience of nature is a major motive for school garden initiatives in high income countries (Williams and Dixon 2013), this is not a major motive for children of farm households in rural areas of Bhutan. In fact, most parents would probably prefer their children to become something other than farmers. This aspect needs careful communication as it may not be obvious to parents why their children need to learn gardening at school, which was an important justification for adding the third component of promotional activities to the intervention design.

\section{Strengths and weaknesses of the study}

Our use of a randomized controlled trial overcomes some of the methodological shortcomings of previous evaluations of school garden interventions as highlighted in Blair (2009), Langellotto and Gupta (2012) and Robinson-O'Brien et al. (2009). To our knowledge, this is the first application of a randomized controlled trial to the evaluation of school gardens in a developing country. Previously published studies have applied such methods to the evaluation of school gardens in the United Kingdom (Hutchinson et al. 2015; Christian et al. 2012; Christian et al. 2014; Evans et al. 2013).

Our study also points at some limitations in using such trials. First, schools are the unit of intervention and it is therefore important to have a large enough sample of schools to yield statistical power to the experiment. This is, however, difficult and costly at a pilot stage, although our sample was larger than most previous studies. Second, this experiment was non-blinded and schools in the control and treatment groups might feel an incentive to change behavior in response to being monitored - called 'observation bias.' A third drawback is that the lag between baseline and endline was relatively short, as is the case in all previous impact studies of school gardens, while behavioral change and height-for-age might take longer to achieve. These limitations cannot be easily overcome. It is therefore critical that more studies are conducted on the impact of school gardens in low income countries.

Possibly as a result of the small sample of schools, we found significant differences in baseline conditions between control and treatment groups (for awareness and to a lesser extent also for preferences; see Table 2). The significant impact found for these variables (Table 3) may be because children in the treatment group started from a lower average position than children in the control group, with both groups obtaining similar average levels at the end of the study. The level of awareness in the treatment group rose by 47.8 percentage points from $28.1 \%$ to $75.9 \%$ while such improvement would have been difficult to achieve in the control group where the baseline level was already $46.5 \%$. It is therefore perhaps likely that the greater scope for improvement in the treatment group resulted in the larger improvement and significant finding. The significant result for the awareness variable, and to lesser extent the preferences variable, must therefore be interpreted with caution.

\section{Conclusion}

There is a growing interest among governments and nongovernmental organizations to promote school gardens in developing countries to address child malnutrition, but evidence for the effect of school gardens has been lacking. Based on our results from 18 schools and 468 schoolchildren in Bhutan, we have provided evidence that school garden interventions in combination with nutritional education, WASH and promotional activities can enhance children's awareness of vegetables, increase their knowledge of sustainable agriculture, stimulate their preferences for eating vegetables, and increase the probability (by 11.7 percentage points) that children include vegetables in their meals. However, our study did not find a significant increase in the number of different vegetables consumed. The application of school gardens to lower income countries will require an approach that is different from higher income countries as changing children's diets requires complementary changes at the community and household level.

Acknowledgements Funding for this research was provided by the Swiss Agency for Development and Cooperation (SDC) under the project "Vegetables Go to School: Improving Nutrition through Agricultural Diversification" and by core donors to the World Vegetable Center: Republic of China (Taiwan), UK Department for International Development (DFID), United States Agency for International Development (USAID), Australian Centre for International Agricultural Research (ACIAR), Germany, Thailand, Philippines, Korea, and Japan. We thank Gueladio Cissé, Axel Drescher, Sévérine Erismann, Rüdiger Glaser, Greg Luther, Maureen Mecozzi, Usha Palaniswamy, Anjal Subba and Carmen Thoenissen for their contributions to this project. We are grateful to this journal's editors and anonymous reviewers for their helpful comments.

\section{Compliance with ethical standards}

Conflict of interests The authors declare that they have no conflict of interest.

Open Access This article is distributed under the terms of the Creative Commons Attribution 4.0 International License (http:// creativecommons.org/licenses/by/4.0/), which permits unrestricted use, distribution, and reproduction in any medium, provided you give appropriate credit to the original author(s) and the source, provide a link to the Creative Commons license, and indicate if changes were made. 


\section{References}

Birch, L. L. (1999). Development of food preferences. Annual Review of Nutrition, 19(1), 41-62. doi:10.1146/annurev.nutr.19.1.41.

Blair, D. (2009). The child in the garden: An evaluative review of the benefits of school gardening. The Journal of Environmental Education, 40(2), 15-38. doi:10.3200/joee.40.2.15-38.

Christian, M. S., Evans, C. E. L., \& Cade, J. E. (2014). Does the royal horticultural society campaign for school gardening increase intake of fruit and vegetables in children? Results from two randomised controlled trials. Public Health Research, 2(4). doi:10.3310 /phr02040.

Christian, M. S., Evans, C. E., Ransley, J. K., Greenwood, D. C., Thomas, J. D., \& Cade, J. E. (2012). Process evaluation of a cluster randomised controlled trial of a school-based fruit and vegetable intervention: Project tomato. Public Health Nutrition, 15(3), 459465. doi:10.1017/s1368980011001844.

Cooke, L. (2007). The importance of exposure for healthy eating in childhood: A review. Journal of Human Nutrition and Dietetics, 20(4), 294-301. doi:10.1111/j.1365-277X.2007.00804.x.

CoRRB. (2014). Annual sap report. Thimphu: Ministry of Agriculture \& Forests.

Evans, C. E., Ransley, J. K., Christian, M. S., Greenwood, D. C., Thomas, J. D., \& Cade, J. E. (2013). A cluster-randomised controlled trial of a school-based fruit and vegetable intervention: Project tomato. Public Health Nutrition, 16(6), 1073-1081. doi:10.1017 /s1368980012005290.

Heim, S., Stang, J., \& Ireland, M. (2009). A garden pilot project enhances fruit and vegetable consumption among children. Journal of the American Dietetic Association, 109(7), 1220-1226.

Hutchinson, J., Christian, M. S., Evans, C. E. L., Nykjaer, C., Hancock, N., \& Cade, J. E. (2015). Evaluation of the impact of school gardening interventions on children's knowledge of and attitudes towards fruit and vegetables. A cluster randomised controlled trial. Appetite, 91, 405-414. doi:10.1016/j.appet.2015.04.076.

Jaime, P. C., \& Lock, K. (2009). Do school based food and nutrition policies improve diet and reduce obesity? Preventive Medicine, 48(1), 45-53. doi:10.1016/j.ypmed.2008.10.018.

Jones, K. M., \& de Brauw, A. (2015). Using agriculture to improve child health: Promoting orange sweet potatoes reduces diarrhea. World Development, 74, 15-24. doi:10.1016/j.worlddev.2015.04.007.

Kelder, S. H., Perry, C. L., Klepp, K. I., \& Lytle, L. L. (1994). Longitudinal tracking of adolescent smoking, physical activity, and food choice behaviors. American Journal of Public Health, 84(7), 1121-1126.

Langellotto, G. A., \& Gupta, A. (2012). Gardening increases vegetable consumption in school-aged children: A meta-analytical synthesis. HortTechnology, 22(4), 430-445.

Lineberger, S. E., \& Zajicek, J. M. (2009). School gardens: Can a handson teaching tool affect students' attitudes and behaviors regarding fruit and vegetables? HortTechnology, 10(3), 593-597.

McAleese, J. D., \& Rankin, L. L. (2007). Garden-based nutrition education affects fruit and vegetable consumption in sixth-grade adolescents. Journal of the American Dietetic Association, 107(4), 662 665. doi:10.1016/j.jada.2007.01.015.

Morgan, P. J., Warren, J. M., Lubans, D. R., Saunders, K. L., Quick, G. I., \& Collins, C. E. (2010). The impact of nutrition education with and without a school garden on knowledge, vegetable intake and preferences and quality of school life among primary-school students. Public Health Nutrition, 13(11), 1931-1940.

Morris, J. L., \& Zidenberg-Cherr, S. (2002). Garden-enhanced nutrition curriculum improves fourth-grade school children's knowledge of nutrition and preferences for some vegetables. Journal of the American Dietetic Association, 102(1), 91-93. doi:10.1016/S00028223(02)90027-1.
Oldewage-Theron, W., \& Egal, A. (2010). Nutrition knowledge and nutritional status of primary school children in qwaqwa. South African Journal of Clinical Nutrition, 23(3), 149-154.

Olsen, A., Ritz, C., Kraaij, L. W., \& Møller, P. (2012). Children's liking and intake of vegetables: A school-based intervention study. Food Quality and Preference, 23(2), 90-98. doi:10.1016/j. foodqual.2011.10.004.

Ozer, E. J. (2007). The effects of school gardens on students and schools: Conceptualization and considerations for maximizing healthy development. Health Education \& Behavior, 34(6), 846-863. doi:10.1177/1090198106289002.

Papke, L. E., \& Wooldridge, J. (1996). Econometric methods for fractional response variables with an application to $401(\mathrm{k})$ plan participation rates. Journal of Applied Econometrics, 11, 619-632.

Parmer, S. M., Salisbury-Glennon, J., Shannon, D., \& Struempler, B. (2009). School gardens: An experiential learning approach for a nutrition education program to increase fruit and vegetable knowledge, preference, and consumption among secondgrade students. Journal of Nutrition Education and Behavior, 41(3), 212-217.

Ratcliffe, M. M., Merrigan, K. A., Rogers, B. L., \& Goldberg, J. P. (2011). The effects of school garden experiences on middle school-aged students' knowledge, attitudes, and behaviors associated with vegetable consumption. Health Promotion Practice, 12(1), 36-43. doi:10.1177/1524839909349182.

Robinson-O'Brien, R., Story, M., \& Heim, S. (2009). Impact of gardenbased youth nutrition intervention programs: A review. Journal of the American Dietetic Association, 109(2), 273-280.

Sharma, M. (2007). International school-based interventions for preventing obesity in children. Obesity Reviews, 8(2), 155-167. doi:10.1111/j.1467-789X.2006.00268.x.

Singh, V., \& West, K. J. (2004). Vitamin a deficiency and xerophthalmia among school-aged children in southeastern asia. European Journal of Clinical Nutrition, 58, 1342-1349.

Skelly, S. M., \& Bradley, J. C. (2007). The growing phenomenon of school gardens: Measuring their variation and their affect on students' sense of responsibility and attitudes toward science and the environment. Applied Environmental Education \& Communication, 6(1), 97-104. doi:10.1080/15330150701319438.

Vidmar, S. I., Cole, T. J., \& Pan, H. (2013). Standardizing anthropometric measures in children and adolescents with functions for egen: Update. Stata Journal, 13(2), 366-378.

Wang, M. C., Rauzon, S., Studer, N., Martin, A. C., Craig, L., Merlo, C., Fung, K., Kursunoglu, D., Shannguan, M., \& Crawford, P. (2010). Exposure to a comprehensive school intervention increases vegetable consumption. Journal of Adolescent Health, 47(1), 74-82. doi:10.1016/j. jadohealth.2009.12.014.

Wansink, B., Just, D. R., Payne, C. R., \& Klinger, M. Z. (2012). Attractive names sustain increased vegetable intake in schools. Preventive Medicine, 55(4), 330-332. doi:10.1016/j. ypmed.2012.07.012.

Williams, D. R., \& Dixon, P. S. (2013). Impact of garden-based learning on academic outcomes in schools. Review of Educational Research, 83(2), 211-235. doi:10.3102/0034654313475824.

World Health Organization. (2007). Who child growth standards: Head circumference-for-age, arm circumference-for-age, triceps skinfoldfor-age and subscapular skinfold-for-age: Methods and development. Geneva: World Health Organization.

Zangmo, U., de Onis, M., \& Dorji, T. (2012). The nutritional status of children in Bhutan: Results from the 2008 national nutrition survey and trends over time. BMC Pediatrics, 12(1), 1-7. doi:10.1186 /1471-2431-12-151. 


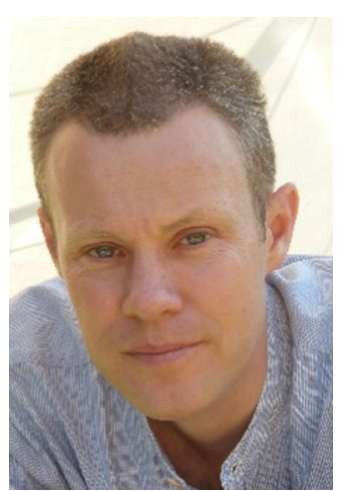

Pepijn Schreinemachers is Lead Scientist - Impact Evaluation at the World Vegetable Center. His expertise is in farming systems research, integrated modeling, and impact evaluation. He holds a $\mathrm{PhD}$ in Agricultural Economics from the University of Bonn, Germany and an MSc in Development Studies from Wageningen University, the Netherlands.

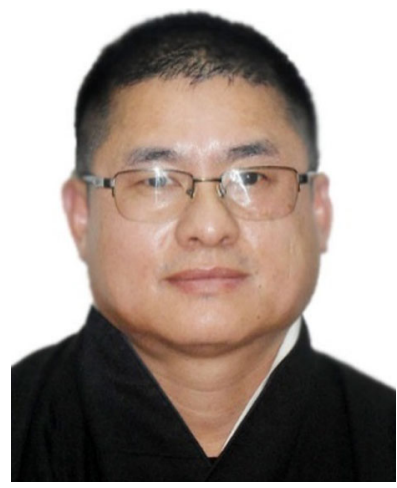

Bal Bdr Rai is National Coordinator of the School Agriculture Programme at the Department of Agriculture, Ministry of Agriculture and Forests, Royal Government of Bhutan. He plans, supports and monitors the green vegetable and small livestock farming in schools as part of vocational education. $\mathrm{He}$ holds a BSc in Agriculture and an MA in Public Administration from the University of Canberra. He is also Country Project Manager for the Vegetables Go to School Project funded by the Swiss Agency for Development and Cooperation (SDC) from 2013-2017. He has vast knowledge of sustainable farming systems in hilly regions.

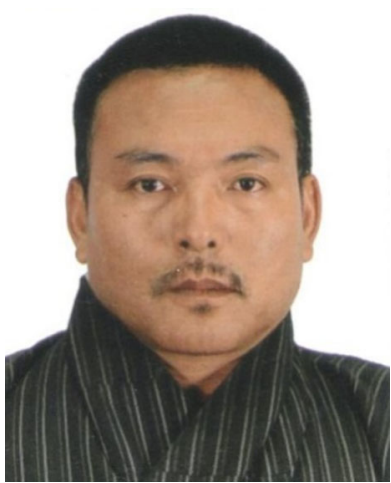

Desang Dorji is Deputy Chief Programme Officer, School Agriculture Programme (SAP), School Health and Nutrition Division (SHND), Department of School Education, Ministry of Education, Royal Government of Bhutan. By profession he is a teacher and served for 9 years as Principal in two schools before his present post. He was coordinator of the school gardening programme from 1986-1994 funded by OXFAM, UK. In 1988-1990, he undertook a diploma course in General Horticulture and Biological Husbandry in Bay of Plenty Polytechnic, Tauranga and Lincoln University, New Zealand. His current responsibilities include implementation of the School Agriculture Programme combined with school Feeding (Nutrition) and Health Programme, and liaising with other relevant organizations. He also facilitates training and workshops for teachers, school cooks and co-facilitates programmes in disaster management at the school and community level.

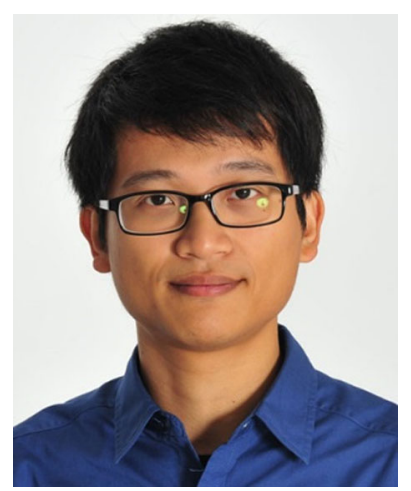

Hsiao-pu Chen is Principal Research Assistant - Impact Evaluation at the World Vegetable Center. He conducts evaluation studies of the center's technologies using quantitative methods. He holds an MSc in Economics and a BA in Political Economics, both from Sun YatSen University, Taiwan.

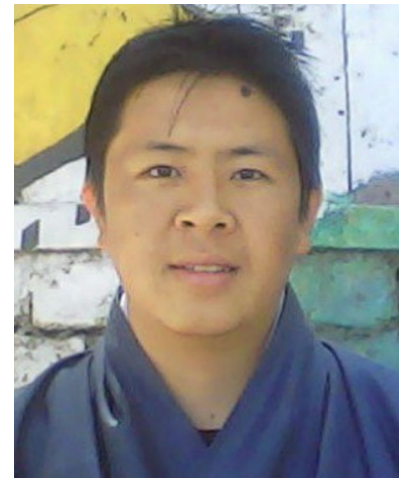

Thinley Dukpa is Assistant Project Manager for the Vegetables Go to School Project in Bhutan. He holds a degree in Economics and Geography from Sherubtse College, Royal University of Bhutan.

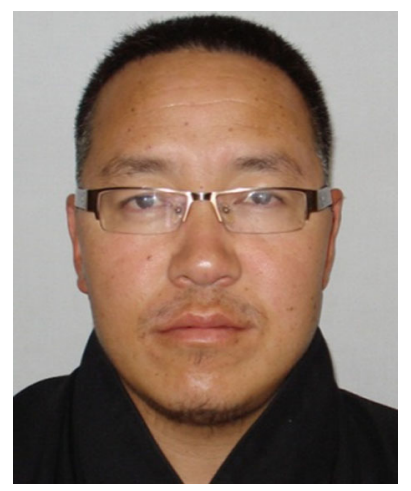

Namgay Thinley is National Coordinator for the National Vegetable Program at the Department of Agriculture, Ministry of Agriculture and Forests, Thimphu, Bhutan. He coordinates the research and development programs and activities for the vegetable sector in Bhutan. He is also a team member of the Vegetables Go to School project. He holds an MSc in International Horticulture from Gottfried Wilhelm Leibniz Universität, Hannover, Germany. 


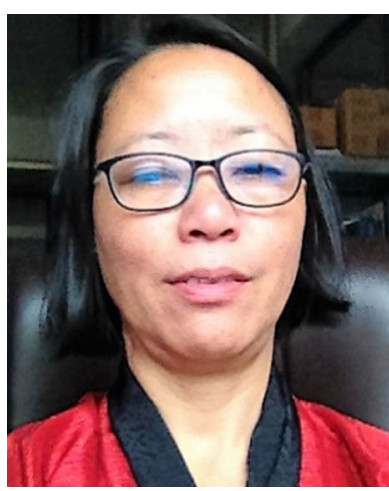

Passang Lhamo Sherpa is a Lecturer in Food, Nutrition and Dietetics at the Faculty of Nursing and Public Health, Kingdom of Bhutan. She is a consultant and member of the National Nutrition Task Force at the Ministry of Health, Department of Nutrition, working with various stakeholders for the improvement of nutritional status and health of the people of Bhutan. She completed her Master's Degree in Food and Nutrition for Development at the Institute of Nutrition, Mahidol University, Thailand.

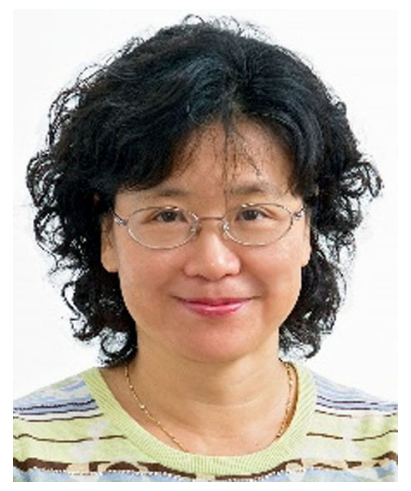

Ray-Yu Yang heads the nutrition group of the World Vegetable Center in Taiwan, specializing in laboratory methods to characterize nutritional and functional properties of vegetables. She works with multidisciplinary teams and develops programs linking agriculture and nutrition to improve diets and health. She received her $\mathrm{PhD}$ in Food and Nutrition from the Institute of Tropical Agriculture and International Cooperation at Ping-Tung University, Taiwan. 